BMJ Open

Diabetes

Research

\& Care

\title{
Recruitment, retention, and training of people with type 2 diabetes as diabetes prevention mentors (DPM) to support a healthcare professional-delivered diabetes prevention program: the Norfolk Diabetes Prevention Study (NDPS)
}

\author{
Nikki J Garner, ${ }^{\oplus 1}$ Melanie Pascale, ${ }^{1}$ Kalman France, ${ }^{1}$ Clare Ferns, ${ }^{1}$ Allan Clark, ${ }^{2}$
} Sara Auckland, ${ }^{1}$ Michael Sampson, ${ }^{\oplus 1,2}$ NDPS Group On behalf of NDPS Group

To cite: Garner NJ, Pascale M, France $\mathrm{K}$, et al. Recruitment, retention, and training of people with type 2 diabetes as diabetes prevention mentors (DPM) to support a healthcare professionaldelivered diabetes prevention program: the Norfolk Diabetes Prevention Study (NDPS). BMJ Open Diab Res Care 2019;7:e000619. doi:10.1136/ bmjdrc-2018-000619

- Additional material is published online only. To view please visit the journal online (http://dx.doi.org/10. 1136bmjdrc-2018-000619).

Received 24 September 2018 Revised 21 April 2019 Accepted 26 April 2019

Check for updates

(c) Author(s) (or their employer(s)) 2019. Re-use permitted under CC BY-NC. No commercial re-use. See rights and permissions. Published by BMJ.

For numbered affiliations see end of article.

Correspondence to Dr Michael Sampson; mike.sampson@nnuh.nhs.uk

\section{ABSTRACT}

Objective Intensive lifestyle interventions reduce the risk of type 2 diabetes in populations at highest risk, but staffing levels are usually unable to meet the challenge of delivering effective prevention strategies to a very large at-risk population. Training volunteers with existing type 2 diabetes to support healthcare professionals deliver lifestyle interventions is an attractive option.

Methods We identified 141973 people at highest risk of diabetes in the East of England, screened 12778 , and randomized 1764 into a suite of type 2 diabetes prevention and screen detected type 2 diabetes management trials. A key element of the program tested the value of volunteers with type 2 diabetes, trained to act as diabetes prevention mentors (DPM) when added to an intervention arm delivered by healthcare professionals trained to support participant lifestyle change.

Results We invited 9951 people with type 2 diabetes to become DPM and 427 responded (4.3\%). Of these, 356 (83.3\%) were interviewed by phone, and of these 131 (36.8\%) were interviewed in person. We then appointed 104 of these 131 interviewed applicants (79\%) to the role (mean age 62 years, $55 \%(n=57)$ male). All DPMs volunteered for a total of 2895 months, and made 6879 telephone calls to 461 randomized participants. Seventy-six (73\%) DPMs volunteered for at least 6 months and 66 (73\%) for at least 1 year. Discussion Individuals with type 2 diabetes can be recruited, trained and retained as DPM in large numbers to support a group-based diabetes prevention program delivered by healthcare professionals. This volunteer model is low cost, and accesses the large type 2 diabetes population that shares a lifestyle experience with the target population. This is an attractive model for supporting diabetes prevention efforts.

\section{INTRODUCTION}

Between 1980 and 2014, the worldwide diabetes population quadrupled to 422 million, with an estimated global prevalence in 2014 of $9.0 \%$ (95\% credible interval $7.2 \%$ $11.1 \%)$ in men and $7.9 \%(6.4 \%-9.7 \%)$ in women. ${ }^{1}$ By 2040, this will increase to 642 million people, more than $90 \%$ of whom will have type 2 diabetes, with a further 318 million people having a preclinical state of impaired glucose regulation. ${ }^{2}$ The enormous impact of type 2 diabetes is recognized by the calls for international focus on this issue ${ }^{13}$ and the need for more effective diabetes prevention strategies. ${ }^{4}$ Effectiveness of lifestyle interventions to prevent or delay type 2 diabetes onset in people at high risk was first documented by randomized controlled trials (RCT) in the $\mathrm{USA}^{5}$ and Finland, ${ }^{6}$ and these lifestyle interventions have shown legacy effects on diabetes incidence reduction. Public Health England conducted a meta-analysis of 16 studies (18 intervention arms) and reported a pooled incidence rate ratio of type 2 diabetes being $26 \%$ lower in those receiving a diabetes prevention program compared with usual care (95\% CI $7 \%$ to $42 \%) .{ }^{7}$ Support for similar interventional models for the effective prevention of type 2 diabetes mellitus has been provided by numerous systematic reviews and meta-analyses. ${ }^{8-10}$ The costs associated with the metformin and lifestyle interventions in the US Diabetes Prevention Program were reported to be modest compared with the placebo intervention ${ }^{11}$ and at 10 -year follow-up lifestyle was indeed cost-effective compared with placebo. ${ }^{12}$ However, the associated financial costs of effective interventions for delivery and implementation can be 


\section{Significance of this study}

What is already known about this subject

- The enormous impactof Type 2 diabetes is recognised by the calls for international focus on thisissue and the need for more effective diabetesprevention strategies

- Research concluded that costs associated with diabetes prevention can bereduced, without any compromise on effectiveness, by using non healthcare-professionals

- There will never beenough healthcare professionals to deliver and meet this huge challenge and peersupporters are an attractive model in limiting costs and supporting existingworkforce. People with existing type 2diabetes are the obvious choice to use in the role of volunteer peer supportersas they are demographically and usually culturally similar to thoseparticipants at risk, are a large enough cohort in any population to developsufficient trainers, share a common experience of being diabetes aware, andface very similar lifestyle challenges

What are the new findings

- Lay members of the public with existing type 2 diabetes can be recruited, trained and retained as lay volunteer mentors (diabetes prevention mentors, DPM) to help support a type 2 diabetes prevention trial in those at highest risk.

- Mentors who remained active until program end averaged a volunteer period of over 3 years in duration.

- The majority of withdrawals (90\%) were related to external circumstances such as change in personal or family health status or existing work commitment

How might these results change the the focus of research or clinical practice?

- As DPMs can be recruited, trained and retained in such a role, can DPMs now be successfully assigned to more senior roles, such as (A) lead mentor, (B) DPM Champion, and/or (C) be involved in trainthe-trainer programs?

- Research should focus on the DPM themselves, namely, does being a DPM have an effect on the volunteer's own glycemic control, that is, do DPMs accrue health benefits from this role?

- Can this DPM model successfully contribute to national diabetes prevention efforts?

high due to staffing and resource use and may be too expensive to implement. A meta-analysis of 28 US-based studies assessed how effective lifestyle interventions held in real-life settings were, which were modeled on the US Diabetes Prevention Program, and concluded that costs associated with diabetes prevention can be reduced, without any compromise on effectiveness, by using non-healthcare professionals (HCP). ${ }^{9}$ There will never be enough HCPs to deliver and meet this huge challenge and peer supporters are an attractive model in limiting costs and supporting the existing workforce. The use of peer supporters codelivering interventions is a growing area of research ${ }^{13-15}$ and individuals tend to volunteer for organizations in which target participants have the same characteristics as themselves. ${ }^{16}$ Systematic review findings of 25 studies, including 14 randomized, controlled and comparative trials, investigated the impact and effect of peer support on diabetes outcomes in adults, and was associated with some modest effects on glycemic control and self-efficacy. ${ }^{17}$ People with existing type 2 diabetes are the obvious choice to use in the role of volunteer peer supporters in diabetes self-management and in diabetes prevention, as they are demographically and usually culturally similar to target participants at risk, are a large enough cohort in any population to develop sufficient trainers share a common experience of being diabetes aware, and face very similar lifestyle challenges. This unique lived and shared experience is absent in generic lay trainer support programs, such as the DESMOND Lay Educator program, where a diagnosis of diabetes was not a selection criterion for peer supporter recruitment. ${ }^{18}$ Using trained individuals with existing type 2 diabetes to help those at risk of developing the condition in collaboration with trained HCPs delivering a lifestyle modification intervention is a novel approach.

The aim of this study is to describe the practicalities associated with recruiting, training and retaining lay individuals with existing type 2 diabetes into a diabetes prevention mentor (DPM) role within the recently completed largest UK diabetes prevention trial. ${ }^{19}$ The DPM worked with trained HCPs to deliver a diabetes prevention intervention in a parallel group RCT testing the value of this model in diabetes prevention, compared with a matched group who received the same intervention without DPM support, and to a control group who received no intervention. A detailed description of the methods involved should help clinicians and policymakers translate this model into practice.

\section{METHODS}

\section{The Norfolk Diabetes Prevention Study}

The Norfolk Diabetes Prevention Study (NDPS) (www. norfolkdiabetespreventionstudy.nhs.uk) is a 7-year program funded by the UK National Institute for Health Research (NIHR RP-PG-0109-10013). The program comprises mass population screening for high-risk individuals, and then tests the efficacy of an intensive 40-month lifestyle intervention in reducing the risk of transition to type 2 diabetes for people with various 'pre-diabetes' or 'non-diabetic hyperglycaemia' combinations. In addition, people with screen-detected type 2 diabetes were also randomized to test for improvement in glycemic control. In total, 1028 people with 'pre-diabetes' and 432 people with screen-detected newly diagnosed type 2 diabetes were randomized into a 3.25-year RCT of a novel diet and lifestyle intervention. The full study protocol is published elsewhere. ${ }^{19}$ The first trial participant was screened for entry to NDPS on 22 August 2011 and the last participant completed the program on 11 April 2018, after an extended screening program duration to reach full accrual, and the program is now closed. The NDPS structure is shown in figure 1.

Eligible study research participants were randomized into one of three study arms: (1) a control group who receive no intervention, (2) a lifestyle modification 
High risk screened eligible participants with an appropriate glycemic category are randomized into a parallel group 46 month intervention trial with three arms : a) a control group that receives trial intervention, $b$ ) an intervention group that receives a lifestyle modification intervention (below) or, c) the same lifestyle intervention with additional support from trained diabetes prevention mentors (DPM) as below

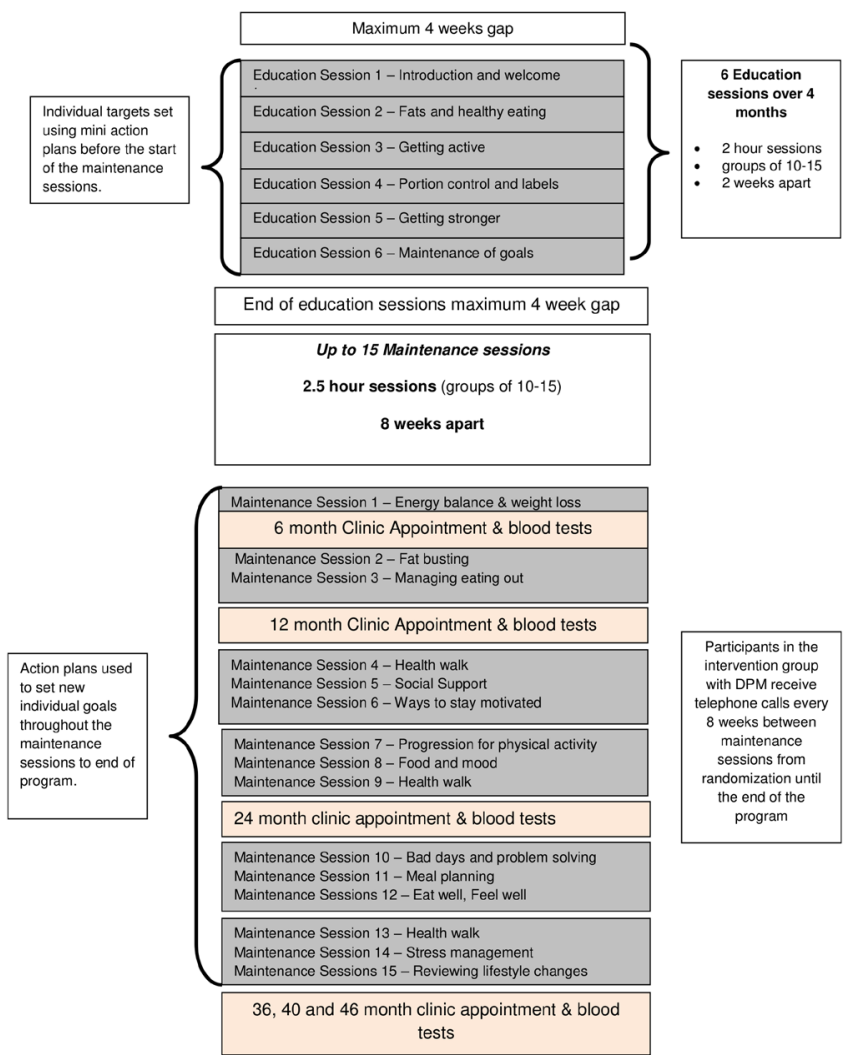

Figure 1 Participant flow, intervention structure, and role of the diabetes prevention mentors (DPM).

intervention group delivered by trained HCPs, or (3) the same lifestyle modification intervention, but with additional support to research trial participants from trained lay volunteers with type 2 diabetes themselves (DPM). The intervention aims to reduce risk of progression to type 2 diabetes through increased physical activity and specific changes in diet and weight loss. The primary outcome was differences in progression rates to type 2 diabetes between these two intervention groups, or glycemic control differences between groups for those with screen-detected type 2 diabetes. Behavior change targets were set by research trial participants, but people were encouraged to think about (and presented the health benefits of) $7 \%$ weight loss, $150 \mathrm{~min} /$ week of moderate-intensity physical activity, two to three sessions of muscle-strengthening exercise per week and reducing intake of total and saturated fat, as these are associated with clinically meaningful changes in diabetes risk for high-risk individuals. ${ }^{60}$ Participants found to have newly diagnosed type 2 diabetes in the screening program ${ }^{19}$ were also randomized to the same control and intervention groups. For research participants randomized to the intervention, or intervention+DPM groups, the lifestyle intervention begins with six 2-hour group-based education/behavior change intervention sessions spread over 12 weeks delivered by trained diabetes prevention facilitators (DPF). After a 4-week gap, this was followed by up to fifteen 2.5-hour group-based maintenance sessions (including behavior maintenance techniques and 50 min of structured exercise) delivered every 8 weeks until program end or 3.25 years' intervention completion, whichever is sooner. Group sizes initially included 10-12 participants, with options to merge groups over time if attendance diminished. The maximum contact time (assuming all maintenance sessions were attended) was 49.5 hours, including 12.5 hours of structured physical activity. Research participants randomized to the intervention+DPM group, in addition, received regular motivational support via telephone from DPM (see the DPM role in the Methods section) to supplement the group sessions delivered by the trained HCPs (DPF). The DPM had no contact with participants in the standard intervention arm or control group, and the lifestyle modification intervention is described elsewhere. ${ }^{1921}$

\section{Recruitment of DPMs}

DPM recruitment was in four stages.

Stage 1 required patients meeting the initial eligibility criteria through database searches conducted by 46 general practice (GP) surgeries in Norfolk, UK. The eligibility criteria used identified potential DPMs who were (A) over 18 years old, and (B) who had been diagnosed with type 2 diabetes for at least 2 years. Invitation letters were sent to 9951 DPM candidates from 46 Norfolk GPs. A DPM Participant Information Sheet and Role Description were included with the expression of interest invitation letters. Any potential DPM interested in the role contacted the study team directly.

Stage 2 was an informal telephone interview conducted by the senior research associate (NJG) with the individual who expressed interest in the role.

Stage 3 was to complete a 'pre-recruitment questionnaire' designed to gather information on the individual's suitability for the role.

Stage 4 was to attend a face-to-face interview $(\mathrm{NJG})$ and one other study team member to discuss the role in more detail.

Only after completing all four stages of recruitment, and if suitable, would the interested individual be offered the role.

\section{The DPM role}

On completion of training, DPMs were assigned up to seven participants randomized to the intervention+DPM group. Assignments of participants to DPM were made based on call availability (preferred days and times of day) provided by both the participant and the DPM. Telephone calls were scheduled once a month for the first 3 months and then once every 2 months until program end or 3.25 years' intervention completion, whichever was sooner. Every DPM received a structured timetable outlining the dates when telephone calls were due to each participant. Telephone calls were programmed to take place between planned session attendances. The dates telephone calls were due to be made to 
the participant were written as week commencing dates and DPMs were told the call must be made to that participant within that week. Information on the initial development and piloting of the DPM recruitment and training is also published elsewhere. ${ }^{22}$ As in a similar mentor intervention, ${ }^{23}$ DPMs were asked to motivate and support research participants, but not to advise or suggest. An important point is that the term 'diabetes prevention mentor', or 'DPM' was chosen by these volunteers themselves to describe their role, and this was supported as part of the trial by Patient and Public Involvement and the lay Participant Advisory Board. It should be noted that the role of a 'mentor' was not to advise, and diabetes prevention motivator might have been an alternative that reflected their role.

\section{DPM's training}

The study-specific training program was designed as a standardized training program to allow for exact replication in future cohorts. Group training seminars were delivered weekly over a 7-week period allowing time for self-reflection and reading between seminars. Each seminar lasted 2.5 hours. The first 30 min offered an informal refresher from the previous session and allowed clarification of outstanding queries. The training had two aims: to provide up-to-date information on physical activity, diet, pre-diabetes and lifestyle-related areas and, second, to undertake practice roleplay work to allow for development of the key skills required for the role. Table 1 outlines the training schedule for group sessions and the content delivered. To successfully complete the group training seminars and move on to the required one-to-one practice work, recruited DPMs were required to attend at least six of the seven sessions (with sessions 3, $4,5,6$, and 7 requiring compulsory attendance). Furthermore, they needed to demonstrate an understanding of the material taught and an ability to put the theory and skills into practice. This was assessed during the seminars which allowed the researchers to become attuned to the strengths of participants and structure their following one-to-one practice training accordingly. The one-to-one practice work consisted of telephone call/s where DPM adopted the role of the mentor and the senior research associate adopted the role of a trial participant. These calls were as close to 'real life' as possible, in preparation for the volunteer to begin their role. The senior research associate (NJG) implemented any situations where they felt the DPM needed to be 'tested'. Table 1 outlines the training schedule for one-to-one training. Bimonthly meetings were also held and content consisted of study updates, refresher skill training, and DPMs were actively encouraged to raise and discuss challenges met during any recent phone calls.

\section{RESULTS}

\section{DPM recruitment}

Stage 1. We invited 9951 people with type 2 diabetes from 46 GPs in the East of England to become a DPM. There were initial responses of interest from 427 (4.3\%) individuals who met the eligibility criteria.
Stage 2. This stage required potential applicants to pass an initial telephone interview evaluating an understanding of the role, commitment and desire to engage and $356(83.3 \%)$ passed this stage.

Stage 3 involved the return of a prerecruitment questionnaire establishing previous experience in mentoring or related field and suitability for the role; 131 out of 356 $(36.8 \%)$ completed this stage.

Stage 4, for those suitable, required a face-to-face interview with the senior research associate and another member of the NDPS staff team; 104 out of 131 (79\%) passed this stage and were offered a place on the training program.

\section{DPM baseline demographics}

The clinical characteristics of the DPM are shown in table 2 .

\section{DPM training evaluations}

Over the study duration, 17 training cohorts consisting of 115 sessions were delivered. All DPMs who attended any training session completed an evaluation form at every session. The main purpose of the evaluations was to assess the perceived quality of the training to allow for improvements to be made prior to the next cohort delivery. Evaluation forms covered six domains of the training (domestic, organization, relevance, course notes, style, content) and measured perceived quality on a 5-point Likert scale. At study end, 485 evaluation forms were included in the analyses, with $97.2 \%$ of the responses answering 'very good' or 'good' across all domains (table 3).

\section{DPM retention and withdrawal}

Ninety-six (92\%) DPMs completed all required trainings and were deemed sufficiently trained to begin making telephone calls (figures 2 and 3). Of those, 93 (89\%) DPMs volunteered for a period of at least 2 months, nearly three-quarters $(\mathrm{n}=76,73 \%)$ volunteered for at least 6 months, and two-thirds $(\mathrm{n}=66,63 \%)$ continued volunteering for at least 1 year. Thirty-eight DPMs volunteered for the full agreed term (36 months), with all bar one deciding to continue their volunteering beyond that agreed term. DPMs who were recruited at any stage throughout the program and who remained active until program end $(n=43 / 104)$, on average volunteered 1198 days; over 3 years (range 362-2441 days), the remaining DPMs who did not withdraw $(\mathrm{n}=10 / 104)$ were categorized as 'finished' as they had completed their initial agreed volunteering term, and at program end had ceased active volunteering. The longest period of volunteering retention was recorded at 111 months from a mentor who commenced the role during an antecedent pilot program and continued involvement into the NDPS.

For the DPM who withdrew from the role $(n=47 / 104)$, number of days actively involved in mentoring ranged from 5 to 1617, with an average of 260 days. Due to the length of this program (2011-2018), withdrawal rates broken down by volunteering duration show that of those 
Table 1 Outline of DPM training schedule

\begin{tabular}{|c|c|c|c|c|c|}
\hline $\begin{array}{l}\text { Timeline (in } \\
\text { weeks) }\end{array}$ & $\begin{array}{l}\text { Training } \\
\text { setting }\end{array}$ & Session details & $\begin{array}{l}\text { PowerPoint } \\
\text { (pp) } \\
\text { presentation }\end{array}$ & $\begin{array}{l}\text { Paired } \\
\text { practice } \\
\text { work }^{*}\end{array}$ & $\begin{array}{l}\text { Practice work } \\
\text { aims }\end{array}$ \\
\hline Week 1 & Group & $\begin{array}{l}\text { Session No: } 1 \\
\text { Session title: Introduction and getting started } \\
\text { Duration: } 2 \text { hours } \\
\text { Topics covered: Research overview, introduction to diabetes } \\
\text { and mentor role and behavior change } \\
\text { Provider: Researcher (chartered psychologist) }\end{array}$ & Yes & No & $\mathrm{n} / \mathrm{a}$ \\
\hline Week 2 & Group & Session No: 2 & Yes & No & $\mathrm{n} / \mathrm{a}$ \\
\hline
\end{tabular}

Session title: Healthy eating and fats

Duration: 2 hours

Topics covered: Healthy eating, eat well guide, vitamins and minerals, fats

Provider: Researcher (chartered psychologist)

\begin{tabular}{|c|c|c|c|c|c|}
\hline Week 3 & Group & $\begin{array}{l}\text { Session No: } 3 \\
\text { Session title: Active listening skills } \\
\text { Duration: } 2.5 \text { hours } \\
\text { Topics covered: Active listening skills-open questions, } \\
\text { summarizing, reflecting back, paraphrasing } \\
\text { Provider: Researcher (chartered psychologist) and learning } \\
\text { facilitator and coach }\end{array}$ & No & Yes & $\begin{array}{l}\text { First practice of } \\
\text { active listening } \\
\text { skills }\end{array}$ \\
\hline Week 4 & Group & $\begin{array}{l}\text { Session No: } 4 \\
\text { Session title: Getting active } \\
\text { Duration: } 2 \text { hours } \\
\text { Topics covered: Physical activity-cardiovascular and resistance } \\
\text { exercise } \\
\text { Provider: Researcher (chartered psychologist) }\end{array}$ & Yes & Yes & $\begin{array}{l}\text { Practice opening } \\
\text { and closing of } \\
\text { a call, practice } \\
\text { active listening } \\
\text { skills for a } 6 \text { min } \\
\text { conversation }\end{array}$ \\
\hline Week 5 & Group & $\begin{array}{l}\text { Session No: } 5 \\
\text { Session title: Portion control and labels } \\
\text { Duration: } 2 \text { hours } \\
\text { Topics covered: Portion control and labels, traffic light system, } \\
\text { ingredients list } \\
\text { Provider: Researcher (chartered psychologist) }\end{array}$ & Yes & Yes & $\begin{array}{l}\text { Practice active } \\
\text { listening skills } \\
\text { for an } 8 \mathrm{~min} \\
\text { conversation }\end{array}$ \\
\hline Week 6 & Group & $\begin{array}{l}\text { Session No: } 6 \\
\text { Session title: Motivational interviewing } \\
\text { Duration: } 2.5 \text { hours } \\
\text { Topics covered: Motivational interviewing-establishing rapport, } \\
\text { expressing empathy, self-efficacy, rolling with resistance, } \\
\text { developing discrepancy } \\
\text { Provider: Researcher (chartered psychologist) and motivational } \\
\text { interviewing trainer }\end{array}$ & No & Yes & $\begin{array}{l}\text { Practice } \\
\text { motivation } \\
\text { interviewing skills } \\
\text { during a } 10 \text { min } \\
\text { conversation }\end{array}$ \\
\hline Week 7 & Group & $\begin{array}{l}\text { Session No: } 7 \\
\text { Session title: Maintaining change } \\
\text { Duration: } 2 \text { hours } \\
\text { Topics covered: Motivation, confidence, importance } \\
\text { Provider: Researcher (chartered psychologist) }\end{array}$ & Yes & Yes & $\begin{array}{l}\text { Practice } \\
\text { motivation } \\
\text { interviewing skills } \\
\text { during a } 14 \text { min } \\
\text { conversation }\end{array}$ \\
\hline & $\begin{array}{l}\text { Training } \\
\text { setting }\end{array}$ & Session details & \multicolumn{3}{|c|}{ Practice work aims } \\
\hline Week 8 & $\begin{array}{l}\text { One to } \\
\text { one }\end{array}$ & $\begin{array}{l}\text { Session title: First practice call } \\
\text { Duration: } 20 \text { min } \\
\text { Provider: Researcher (chartered psychologist) }\end{array}$ & \multicolumn{3}{|c|}{$\begin{array}{l}\text { Assessment of opening and closing the call } \\
\text { and the use of skills taught for a total call } \\
\text { length of } 15 \mathrm{~min} .\end{array}$} \\
\hline $\begin{array}{l}\text { Week } 9 \text { (and } \\
\text { onwards if } \\
\text { additional } \\
\text { practice } \\
\text { required) }\end{array}$ & $\begin{array}{l}\text { One to } \\
\text { one }\end{array}$ & $\begin{array}{l}\text { Session title: Additional practice call/s (if needed) } \\
\text { Duration: } 20 \text { min } \\
\text { Provider: Researcher (chartered psychologist) }\end{array}$ & \multicolumn{3}{|c|}{$\begin{array}{l}\text { Additional practice call conducted if skills } \\
\text { were not up to standard at first call. Calls } \\
\text { conducted until both parties are confident in } \\
\text { peer supporters' ability. }\end{array}$} \\
\hline
\end{tabular}

*'Paired Practice Work' means being placed with a partner (a fellow DPM being trained) and conducting a role-play-based telephone call. This is usually conducted with DPM sitting back-to-back as to not be distracted by facial expressions.

DPM, diabetes prevention mentor; $\mathrm{n} / \mathrm{a}$, not applicable.

DPMs who withdrew, a quarter $(\mathrm{n}=11,23 \%)$ of DPMs withdrew prior to volunteering for a period of 2 months and just over half $(\mathrm{n}=28,60 \%) \%$ withdrew prior to volunteering for 6 months or greater. Of those who withdrew, nearly half still actively volunteered for a period of 6 months or more. At study end, DPM withdrawal rate 


\begin{tabular}{|c|c|c|c|c|}
\hline & & $\begin{array}{l}\text { Total } \\
\text { n (\%) }\end{array}$ & $\begin{array}{l}\text { Male } \\
\mathrm{n}(\%)\end{array}$ & $\begin{array}{l}\text { Female } \\
\text { n (\%) }\end{array}$ \\
\hline \multirow{5}{*}{$\begin{array}{l}\text { Previous counseling } \\
\text { experience }\end{array}$} & Total & $104(100)$ & $57(100)$ & $47(100)$ \\
\hline & Previous training in counseling & $68(65.3)$ & $40(70.1)$ & $28(59.6)$ \\
\hline & No previous training in counseling & $12(11.5)$ & $6(10.5)$ & $6(12.8)$ \\
\hline & No response & $16(15.4)$ & $6(10.5)$ & $10(21.3)$ \\
\hline & Data not available & $8(7.7)$ & $5(8.8)$ & $3(6.4)$ \\
\hline \multirow[t]{7}{*}{ Diabetes diagnosis duration } & Total & $104(100)$ & $57(100)$ & $47(100)$ \\
\hline & $2-4$ years & $15(14.4)$ & $9(15.9)$ & $6(12.8)$ \\
\hline & $4-8$ years & $33(31.8)$ & $16(28.0)$ & $17(36.1)$ \\
\hline & $8-12$ years & $19(18.3)$ & $16(28.0)$ & $3(6.4)$ \\
\hline & $12+$ years & $16(15.4)$ & $6(10.5)$ & $10(21.3)$ \\
\hline & No response & $13(12.5)$ & $5(8.8)$ & $8(17.0)$ \\
\hline & Data not available & $8(7.7)$ & $5(8.8)$ & $3(6.4)$ \\
\hline \multirow[t]{6}{*}{ Smoking status } & Total & $104(100)$ & $57(100)$ & $47(100)$ \\
\hline & Smokers & $5(4.8)$ & $4(7.0)$ & $1(2.1)$ \\
\hline & Non-smokers & $45(43.3)$ & $24(42.1)$ & $21(44.7)$ \\
\hline & Ex-smokers & $35(33.7)$ & $20(35.1)$ & $15(32.0)$ \\
\hline & No response & $11(10.6)$ & $4(7.0)$ & $7(14.9)$ \\
\hline & Data not available & $8(7.7)$ & $5(8.8)$ & $3(6.4)$ \\
\hline \multirow[t]{6}{*}{ Treatment control method } & Diet and exercise only & $17(16.3)$ & $11(19.3)$ & $6(12.8)$ \\
\hline & Oral hypoglycemics only & $43(41.3)$ & $24(42.1)$ & $19(40.4)$ \\
\hline & Insulin & $5(4.8)$ & $2(3.5)$ & $3(6.4)$ \\
\hline & Oral hypoglycemics and insulin & $4(3.8)$ & $2(3.5)$ & $2(4.3)$ \\
\hline & Diet and exercise+tablets & $13(12.5)$ & $8(14.0)$ & $5(10.6)$ \\
\hline & Diet and exercise+tablets+insulin & $3(2.9)$ & $0(0.0)$ & $3(6.4)$ \\
\hline \multirow[t]{7}{*}{ Health status } & Total & $104(100)$ & $57(100)$ & $47(100)$ \\
\hline & Excellent & $9(8.7)$ & $6(10.5)$ & $3(6.4)$ \\
\hline & Good & $53(51.0)$ & $26(45.6)$ & $27(57.4)$ \\
\hline & Average & $21(20.2)$ & $13(22.8)$ & $8(17.0)$ \\
\hline & Fair & $2(1.9)$ & $2(3.5)$ & $0(0.0)$ \\
\hline & No response & $11(10.6)$ & $5(8.8)$ & $6(12.8)$ \\
\hline & Data not available & $8(7.7)$ & $5(8.8)$ & $3(6.4)$ \\
\hline \multirow{5}{*}{$\begin{array}{l}\text { Comorbidity status } \\
\text { (any other diagnosed } \\
\text { condition) }\end{array}$} & Total & $104(100)$ & $57(100)$ & $47(100)$ \\
\hline & Yes & $59(56.7)$ & $29(50.9)$ & 30 (63.9) \\
\hline & No & $22(21.1)$ & 17 (29.9) & $5(10.6)$ \\
\hline & No response & $15(14.4)$ & $6(10.5)$ & $9(19.1)$ \\
\hline & Data not available & $8(7.7)$ & $5(8.8)$ & $3(6.4)$ \\
\hline
\end{tabular}

*19 diabetes prevention mentors (DPM) did not return data on treatment regimen in prerecruitment questionnaire so $\mathrm{n}=85$ for this variable

concluded at $45 \%(\mathrm{n}=47)$. Of all withdrawals, only $10 \%$ $(\mathrm{n}=5)$ were study related, that is, being unable to commit to the required time to making telephone calls. The majority of withdrawals $(n=46,90 \%)$ related to external circumstances and situations such as change in personal or family health status $(47 \%)$ or existing work commitments $(45 \%)$. Twenty-eight $(60 \%)$ of all withdrawn DPMs were male. These data are shown in figures 2 and 3 and details on withdrawals, including duration and reasons given, are shown in online supplementary table A.

Differences at baseline between DPMs who withdrew within 6 months of recruitment and those who continued beyond 6 months

There were no significant differences between DPMs who withdrew from the program before 6 months $(n=28)$ 
Table 3 Quantitative responses from diabetes prevention mentor training evaluations $(n=485)$

\begin{tabular}{|c|c|c|c|c|c|c|}
\hline & Very good & Good & Average & Poor & Very poor & Missing data \\
\hline & n (\%) & n (\%) & n (\%) & n (\%) & n (\%) & n (\%) \\
\hline $\begin{array}{l}\text { Domestic } \\
\text { (housekeeping/catering/room } \\
\text { layout/facilities) }\end{array}$ & $325(67.0)$ & $133(28.4)$ & $23(4.7)$ & $2(0.4)$ & $0(0.0)$ & $2(0.4)$ \\
\hline Organization & 399 (82.3) & 80 (16.5) & $4(0.8)$ & $0(0.0)$ & $0(0.0)$ & $2(0.4)$ \\
\hline Relevance & $406(83.7)$ & 73 (15.1) & $3(0.6)$ & $0(0.0)$ & $0(0.0)$ & $2(0.4)$ \\
\hline Course notes & $388(80)$ & 78 (16.1) & $5(1.0)$ & $3(0.6)$ & $0(0.0)$ & $11(2.3)$ \\
\hline Style & 415 (85.6) & 59 (12.2) & $3(0.6)$ & $0.0(0.0)$ & $1(0.2)$ & $6(1.2)$ \\
\hline Content & 405 (83.5) & 63 (13.0) & $6(1.2)$ & $0(0.0)$ & $0(0.0)$ & $11(2.3)$ \\
\hline
\end{tabular}

and those who were retained for more than 6 months in mean age $(61.5(8.9)$ vs $62.4(8.2)$ years; $\mathrm{p}=0.61)$, in mean HbAlc (60.0 (19.2) vs 54.9 (12.3) $\mathrm{mmol} / \mathrm{mol} ; \mathrm{p}=0.20)$, in gender $(\mathrm{p}=0.46)$, or in distribution of diabetes treatment modality at baseline $(\mathrm{p}=0.079)$. DPMs who were retained in the program at 6 months were more likely to have previous counseling or training experience $(50 / 76$; $85 \%)$ than those who withdrew before 6 months $(16 / 28$; $67 \%)$, but this difference was not significant $(\mathrm{p}=0.064)$. Body mass index was not tracked.

\section{DISCUSSION}

In a large type 2 diabetes prevention program, we successfully recruited a large cohort of trained volunteers with existing type 2 diabetes as (DPM) to codeliver a diabetes prevention lifestyle intervention offering peer support to randomized participants.

It is well recognized that individuals tend to volunteer for organizations in which individuals have the same characteristics as themselves. ${ }^{16}$ Participant feedback from the DESMOND study highlighted that those participants who engaged with volunteers who also had diabetes, saw this

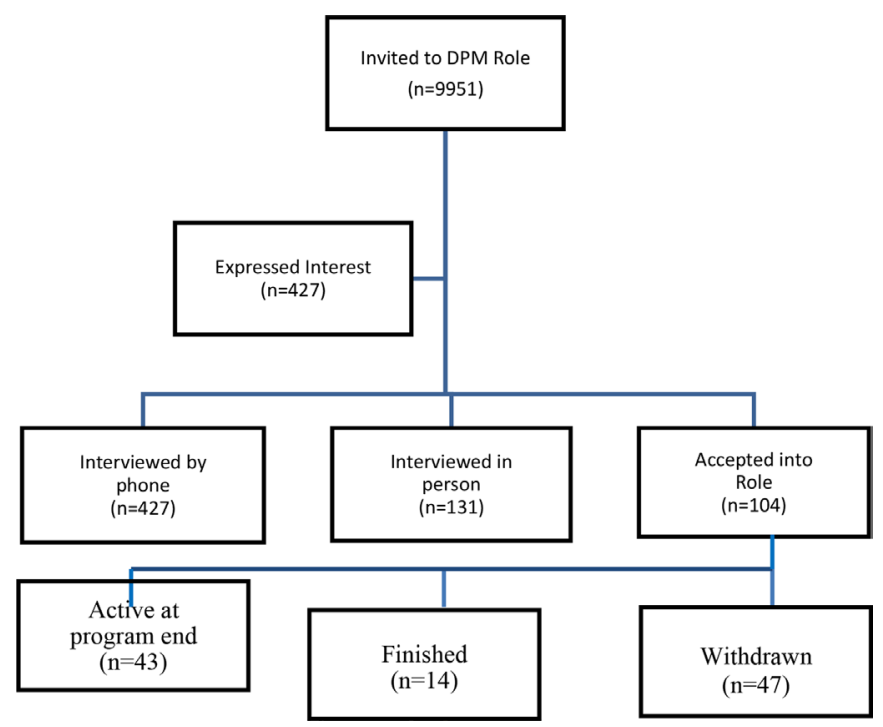

Figure 2 Recruitment into diabetes prevention mentor (DPM) role in the Norfolk Diabetes Prevention Study.

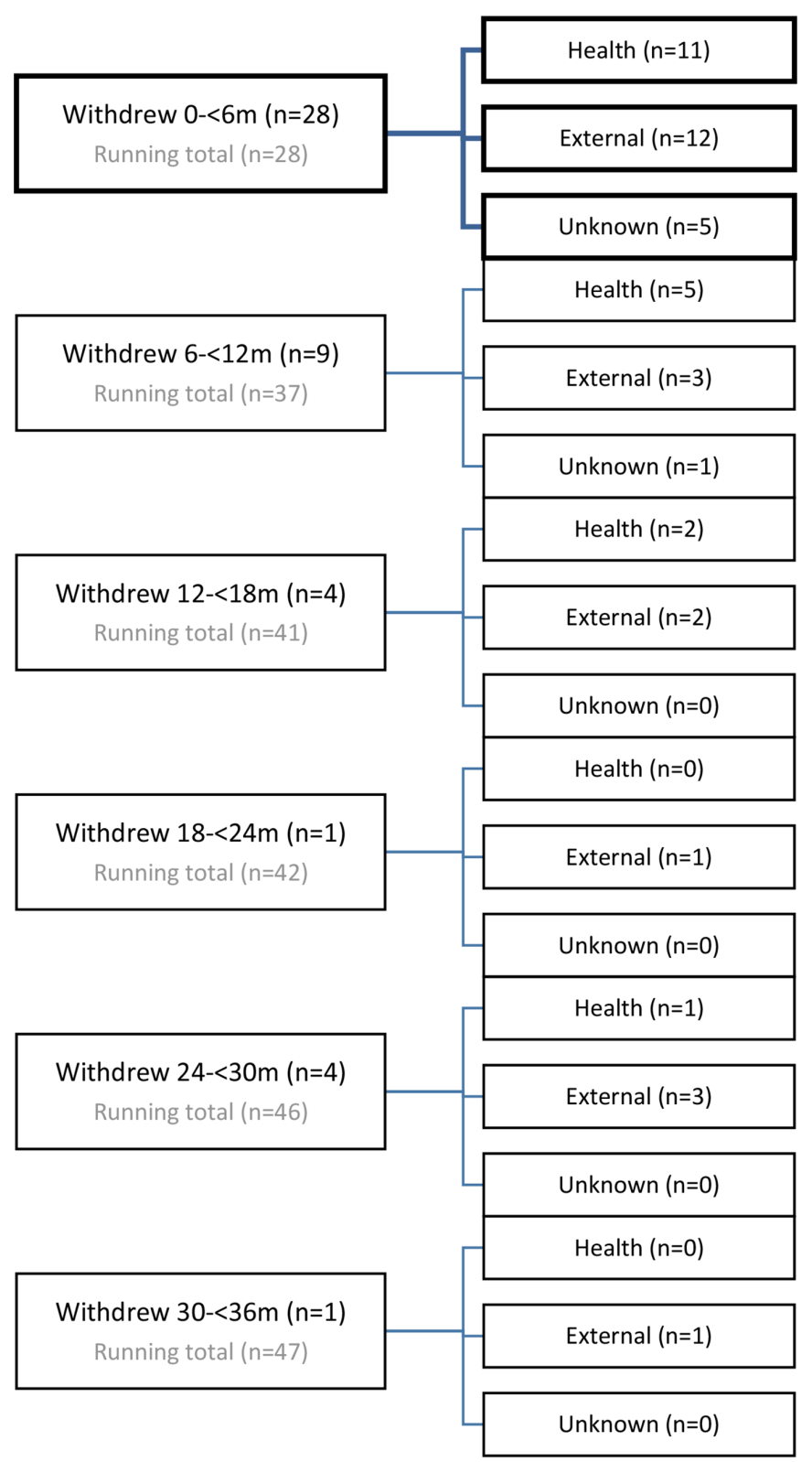

Figure 3 Retention of diabetes prevention mentors (DPM) in the Norfolk Diabetes Prevention Study (NDPS): n=104 DPMs at baseline. 
as positive attribute. A sample of patients, lay volunteers and HCPs involved in delivering the DESMOND program were interviewed by telephone and it was suggested that the use of lay individuals as educators was acceptable to all. ${ }^{18}$ Results of the DESMOND program resulted in greater weight loss but no difference in hemoglobin A1c levels 12 months after diagnosis, with no significant change found for either at 3-year follow-up. ${ }^{24}{ }^{25}$ To ensure that shared experience, the current study only recruited individuals with existing type 2 diabetes to mentor those who were either at risk of developing the condition or who were newly diagnosed with type 2 diabetes. This shared experience should be encouraged when recruiting peer supporters ${ }^{18}$ rather than employing volunteers who have a generic chronic condition.

A comprehensive training program was devised and successfully evaluated by the DPMs themselves. We found attendance and participation levels to be high and consistent among those who entered the training program. Previous research has noted that some peer supporters have reported that using roleplay was awkward and uncomfortable,${ }^{26}$ yet qualitative feedback obtained from all DPMs who attended NDPS training suggested that role-play methods used were agreeable and welcomed. Across the literature, there is a large variation in the training offered to volunteers in the amount of hours and in the content delivered. Similar research with volunteers has reported training durations ranging from 5 hours in some studies ${ }^{27}$ to 50 hours in others. ${ }^{28}$ The intensity of the training is dependent on the nature of the peer supporters' role. Simmons ${ }^{29}$ suggested the nature of the role can differ, ranging from natural companion (basic peer support) up to a paraprofessional level. Paraprofessionals can involve the individual having an explicit health service role and/or having been trained in specific techniques (ie, motivational interviewing). Researchers have attempted to classify the intensity of training programs into three categories (low, moderate and high) dependent on contact hours. A low-intensity training included a brief 3-hour session teaching empowerment skills and behavior change strategies. ${ }^{30}$ A moderate-intensity training involved peer supporters completing a 4-day workshop which trained them to deliver a scripted six-session diabetes self-management program. ${ }^{31}$ Finally, a high-intensity example consisted of peer supporters attending an 18-session program followed by delivery of 33 supervised simulated education sessions. ${ }^{32}$ In the limited literature describing assessment procedures, peer supporters were reviewed after training and underwent practice examination, and those who were qualified were allowed to perform the peer role. ${ }^{33}$ Further research on the training and management of volunteers in healthcare settings is needed. ${ }^{34}$ The present study provides evidence that training sessions across cohorts were well attended, received positive evaluations and that volunteers can be trained in the required skill sets in a training program of less than 20 hours. If a training program can be successfully delivered with a significant reduction in contact hours, this could have great financial implications in respect of staffing required to deliver the training.

Other than requiring a dedicated staff member, currently little is known about the specifics and amount of supervision needed for peer supporter roles for optimal retention and effectiveness, ${ }^{35}$ with some literature reporting a member of the research team contacting peer supporters monthly by phone. ${ }^{1327}$ Simmons et $a l^{26}$ reported a $50 \%$ withdrawal rate of volunteers after a 2-month period, compared with an $11 \%$ withdrawal rate over a similar time period in this program. In relation to the present study, one aspect that should be noted is the significant length of volunteering duration by DPM. Three-quarters of all recruited DPMs volunteered for at least 6 months, two-thirds volunteered for over a year and nearly all DPMs who had the opportunity to volunteer for the full agreed term of 3 years decided to continue volunteering past their initial term. Training and support are critical factors in establishing retention and commitment to the volunteer role. We found no significant baseline differences between DPMs who withdrew before 6 months compared with those who persisted beyond 6 months in age, gender, diabetes treatment, or previous counseling experience. It is possible that the relatively intense level of personal support offered to the DPM by the research team during recruitment and in program, with a single point of contact (NJG) contributed to high retention rates compared with other models. There was a non-significant trend $(p=0.064)$ towards higher DPM retention rates at 6 months among those who had had some previous counseling experience, but there were no other significant clinical differences at baseline in those who were retained by 6 months or those who had withdrawn. We chose to analyze at 6 months as most of the comparable literature on retention has been relatively short duration, and to enhance ongoing DPM retention further blood testing and analyses in this volunteer population after baseline are incomplete.

Interventions to change behavior have enormous potential to alter current patterns of disease and this is a widely translatable and novel model to be considered as an additional element within existing programs offered in the fields of diabetes, prevention and overall health. Programs such as the UK Diabetes Prevention Programme are commissioned and funded nationally and implemented by national and regional teams. ${ }^{36}$ An alternative is for lay individuals to codeliver interventions using telephone communication which has been shown to be acceptable to patients ${ }^{37}$ and may be preferred as a method of contact. Telephone-delivered interventions have an appeal as they allow coverage over a wider area, provide anonymity that face-to-face mentoring cannot, and circumvent potential confidentiality 
and safety issues. Interventions for successful behavioral change must develop and maintain supportive social networks and nurturing relationships to provide practical help, emotional support, praise or reward. ${ }^{38} 39$ Employing a volunteer model such as this accesses the type 2 diabetes population with shared experience and interest in diet and lifestyle as the target population at risk, and is low cost as the volunteers do not require an HCP salary, and carry no direct costs apart from limited travel expenses. It should be stressed that within the context of the NDPS trials, the recruitment process is time intensive with phone interviews, in-person interviews and substantial support from the research team.

The full health economic modeling for the models in NDPS will be undertaken once the primary outcomes are reported.

The use of lay volunteer health workers, or community health workers, to deliver lifestyle modification intervention in a clinical setting for people at high risk of type 2 diabetes, or with type 2 diabetes, is well described. ${ }^{9}{ }^{1740-43}$ These workers have generally been non-professional volunteers without a healthcare background, but with training to deliver a specific healthcare intervention to a familiar target population. ${ }^{9}{ }^{1739-43}$ It should be emphasized that the DPMs with type 2 diabetes in this study were not entirely representative of the general lay population, as $65 \%$ had some experience counseling or training prior to recruitment, and all had type 2 diabetes.

This is an attractive model in terms of limiting salary costs and expanding the prevention workforce with workers who usually share a common life experience, ${ }^{33}$ and people with type 2 diabetes are an obvious choice for this role. Only one other study has used people with type 2 diabetes as part of a diabetes prevention trial to prevent diabetes, ${ }^{44}$ although it is unknown if this translated into a lower type 2 diabetes incidence, but these studies frequently show improvements in surrogates for diabetes risk. ${ }^{9}{ }^{17} 40-4345$ In type 2 diabetes, available lay volunteer studies have generally been clinical interventions in high-income countries targeting minority diabetes populations in low-income settings. ${ }^{46}$ They have commonly delivered a standard curriculum, or provided informational and emotional support in addition to HCPs, and have usually been integrated into clinical teams. ${ }^{46}$ These data also suggest a modest impact of 'peer support' in terms of improved glycemic control in target type 2 diabetes populations. ${ }^{40}$ The use of people with existing type 2 diabetes to act as peer supporters in self-management program for other people with type 2 diabetes is less common in a research or clinical context and has been of modest benefit in some clinical settings. ${ }^{47}$ As far as we are aware, the model described here is the first time trained volunteers with existing type 2 diabetes have been used in an adequately powered randomized trial to supplement a lifestyle modification intervention delivered by HCPs to prevent or manage type 2 diabetes. The detailed description of the methods involved in recruiting, training and retaining volunteers in such a role will assist policymakers and clinicians to translate this model into further practice.
Jenkinson et $a l \mathrm{~s}^{48}$ systematic review of 5 RCTs (7 papers), 4 non-RCTs, and 17 cohort studies (29 papers) examined the effects of formal volunteering on volunteers' physical and mental health. Cohort studies showed volunteering had favorable effects on mental health (depression, life satisfaction and well-being). Research must investigate the fine line between volunteering enough to experience mental health benefits, that is, up to 10 hours/month, ${ }^{49}$ and volunteering so much time that it becomes a burden leading to burnout. ${ }^{50}$ There may of course be additional mental and physical health benefits that accrue to the DPM in this program. In this study, all DPMs received training and consistent, regular supervision on national policy guidelines for healthy eating and physical activity, which may act as influences to their own behavior change. The model offers real opportunities to develop a new volunteer workforce with type 2 diabetes who have a shared interest in diet, lifestyle and glycemic outcomes to the participants they are supporting in a diabetes prevention intervention.

\section{Author affiliations}

${ }^{1}$ Elsie Bertram Diabetes Centre, Norfolk and Norwich University Hospital NHS Foundation Trust, Norwich, UK

${ }^{2}$ Norwich Medical School, University of East Anglia, Norwich, UK

Acknowledgements The authors are grateful to the Norfolk and Norwich University Hospitals NHS Foundation Trust as sponsor. The authors thank all the DPMs for their time and commitment to the study and their participants, and acknowledge the members of the Norfolk Diabetes Prevention Study Group: Max Bachmann, Garry Barton, Allan Clark, Ketan Dhatariya, Clare Ferns, Colin Greaves, Martin Hadley-Brown, Amanda Howe, Lisa Irvine, Garry John, David Rea, Jane Smith, Jeremy Turner, Rebecca Usher, and Tara Wallace.

Collaborators NDPS Group: Sara Auckland, Max Bachmann, Garry Barton, Ketan Dhatariya, Colin Greaves, Martin Hadley-Brown, Amanda Howe, Lisa Irvine, Garry John, Rebecca Usher, David Rea, Jane Smith, Jeremy Turner, Tara Wallace.

Contributors NJG led the recruitment, training and supervision of DPM, researched data, and led the writing of the manuscript. MP as program manager reviewed the manuscript and contributed with recruitment. KF contributed to retention and supervision of DPM. SA reviewed the manuscript and contributed to recruitment. MS as chief investigator and guarantor reviewed and edited the manuscript. All authors read and approved the final manuscript.

Funding The study was funded by the National Institute for Health Research (NIHR) under its Programme Grants for Applied Research (Reference No: RP-PG0109-10013). Additional funding came from the NIHR Clinical Research Network (Eastern) and the Norfolk and Norwich University Hospital NHS Trust.

Disclaimer The views expressed are those of the author(s) and not necessarily those of the NHS, the NIHR or the Department of Health. The funding source(s) had no role in data collection, writing or any version of this manuscript.

Competing interests None declared.

Patient consent for publication Obtained.

Ethics approval The study was approved by East of England (REC 2011).

Provenance and peer review Not commissioned; externally peer reviewed.

Data availability statement Data are available upon reasonable request. All data relevant to the study are included in the article or uploaded as supplementary information.

Open access This is an open access article distributed in accordance with the Creative Commons Attribution Non Commercial (CC BY-NC 4.0) license, which permits others to distribute, remix, adapt, build upon this work non-commercially, and license their derivative works on different terms, provided the original work is properly cited, appropriate credit is given, any changes made indicated, and the use is non-commercial. See: http://creativecommons.org/licenses/by-nc/4.0/. 


\section{REFERENCES}

1. NCD. Worldwide trends in diabetes since 1980: a pooled analysis of 751 population-based studies with 4.4 million participants. The Lancet 2016;387:1513-30.

2. International Diabetes Federation. IDF diabetes atlas, 7th EDN, 2015. Available: https://www.idf.org/e-library/epidemiology-research/ diabetes-atlas.htm [Accessed 6 Dec 2018].

3. World Health Organisation (WHO). Global action plan for the prevention and control of non - communicable diseases 2013 2020, 2013. Available: https://www.who.int/nmh/events/ncd_action_ plan/en/ [Accessed 6 Dec 2018].

4. Chan JCN, Gregg EW, Sargent J, et al. Reducing global diabetes burden by implementing solutions and identifying gaps: a Lancet Commission. Lancet 2016;387:1494-5.

5. Tuomilehto J, Lindström J, Eriksson JG, et al. Prevention of type 2 diabetes mellitus by changes in lifestyle among subjects with impaired glucose tolerance. N Engl J Med 2001;344:1343-50.

6. Knowler WC, Barrett-Connor E, Fowler SE, et al. Reduction in the incidence of type 2 diabetes with lifestyle intervention or metformin. N Engl J Med 2002;346:393-403.

7. Ashra NB. A systematic review and meta-analysis assessing the effectiveness of pragmatic lifestyle interventions for the prevention of type 2 diabetes mellitus in routine practice. London: Public Health England, 2015.

8. Gillies CL, Abrams KR, Lambert PC, et al. Pharmacological and lifestyle interventions to prevent or delay type 2 diabetes in people with impaired glucose tolerance: systematic review and metaanalysis. BMJ 2007;334.

9. Ali MK, Echouffo-Tcheugui J, Williamson DF. How effective were lifestyle interventions in real-world settings that were modeled on the diabetes prevention program? Health Aff 2012;31:67-75.

10. Cardona-Morrell M, Rychetnik L, Morrell SL, et al. Reduction of diabetes risk in routine clinical practice: are physical activity and nutrition interventions feasible and are the outcomes from reference trials replicable? A systematic review and meta-analysis. BMC Public Health 2010;10.

11. Hernan WH, Brandle M, Zhang $P$, et al. Costs associated with the primary prevention of type 2 diabetes mellitus in the diabetes prevention program. Diabetes Care 2003;26:36-47.

12. Diabetes Prevention Program Research Group. The 10 -year costeffectiveness of lifestyle intervention or metformin for diabetes prevention: an intent-to-treat analysis of the DPP/DPPOS. Diabetes Care 2012;35:723-30.

13. de Vries L, van der Heijden AAWA, van 't Riet E, et al. Peer support to decrease diabetes-related distress in patients with type 2 diabetes mellitus: design of a randomised controlled trial. BMC Endocr Disord 2014;14.

14. Xie B, Ye X-li, Sun Z-lin, et al. Peer support for patients with type 2 diabetes in rural communities of China: protocol for a cluster randomized controlled trial. BMC Public Health 2014;14.

15. Chan JCN, Sui Y, Oldenburg B, et al. Effects of Telephone-Based peer support in patients with type 2 diabetes mellitus receiving integrated care. JAMA Intern Med 2014;174:972-81.

16. Chambré SM. Volunteers as witnesses: the mobilization of AIDS volunteers in New York City, 1981-1988. Soc Serv Rev 1991;65:531-47.

17. Dale JR, Williams SM, Bowyer V. What is the effect of peer support on diabetes outcomes in adults? A systematic review. Diabet Med 2012;29:1361-77.

18. Mandalia PK, Stone MA, Davies MJ, et al. Diabetes selfmanagement education: Acceptability of using trained lay educators. Postgrad Med J 2014;90:638-42.

19. Pascale M, Murray N, Bachmann M, et al. Study Protocol: The Norfolk Diabetes Prevention Study [NDPS]: a 46 month multi centre, randomised, controlled parallel group trial of a lifestyle intervention [with or without additional support from lay lifestyle mentors with Type 2 diabetes] to prevent transition to Type 2 diabetes in high risk groups with non - diabetic hyperglycaemia, or impaired fasting glucose. BMC Public Health 2017;17.

20. Schwarz PE, Greaves CJ, Lindström J, et al. Nonpharmacological interventions for the prevention of type 2 diabetes mellitus. Nat Rev Endocrinol 2012;8:363-73.

21. Murray NJ, Abadi S, Blair A, et al. The importance of type 2 diabetes prevention: the norfolk diabetes prevention study. $\mathrm{Br} J$ Diabetes Vasc Dis 2011;11:308-13.

22. Murray NJ, Gasper AV, Irvine L, et al. A motivational peer support program for type 2 diabetes prevention delivered by people with type 2 diabetes: the UEA-IFG feasibility study. Diabetes Educ 2012;38:366-76.

23. Johansson T, Keller S, Winkler H, et al. Effectiveness of a peer support programme versus usual care in disease management of diabetes mellitus type 2 regarding improvement of metabolic control: a cluster-randomised controlled trial. J Diabetes Res 2016;2016:1-10.

24. Davies MJ, Heller S, Skinner TC, et al. Effectiveness of the diabetes education and self management for ongoing and newly diagnosed (DESMOND) programme for people with newly diagnosed type 2 diabetes: cluster randomised controlled trial. BMJ 2008;336:491-5.

25. Khunti K, Gray LJ, Skinner T, et al. Effectiveness of a diabetes education and self management programme (DESMOND) for people with newly diagnosed type 2 diabetes mellitus: three year followup of a cluster randomised controlled trial in primary care. BMJ 2012;344:e2333.

26. Simmons D, Prevost AT, Bunn C, et al. Impact of community based peer support in type 2 diabetes: a cluster randomised controlled trial of individual and/or group approaches. PLoS One 2015;10:e0120277

27. Paul G, Keogh K, D'Eath M, et al. Implementing a peer-support intervention for people with type 2 diabetes: a qualitative study. Fam Pract 2013;30:593-603.

28. Cummings DM, Lutes LD, Littlewood K, et al. Empower: a randomized trial using community health workers to deliver a lifestyle intervention Program in African American women with type 2 diabetes: design, rationale, and baseline characteristics. Contemp Clin Trials 2013;36:147-53.

29. Simmons D. Peer support: time to TAP the (largely) untapped. European Diabetes Nursing 2013;10:98-103.

30. Heisler M, Piette JD. "I help you, and you help me": facilitated telephone peer support among patients with diabetes. Diabetes Educ 2005;31:869-79.

31. Lorig K, Ritter PL, Villa FJ, et al. Community-based peer-led diabetes self-management: a randomized trial. Diabetes Educ 2009;35:641-51.

32. Baksi AK, Al-Mrayat M, Hogan D, et al. Peer advisers compared with specialist health professionals in delivering a training programme on self-management to people with diabetes: a randomized controlled trial. Diabet Med 2008;25:1076-82.

33. Deng K, Ren Y, Luo Z, et al. Peer support training improved the glycemic control, insulin management, and diabetic behaviors of patients with type 2 diabetes in rural communities of central China: a randomized controlled trial. Med Sci Monit 2016;22:267-75.

34. Casiday R, Kinsman E, Fisher C, et al. Volunteering and health; what impact does it really have. London: Volunteering England, 2008.

35. World Health Organisation (WHO). Community based health workers $(\mathrm{CHW})$ : WHO guidelines on health policy and system support to optimize community based health worker programmes. Available: https://www.who.int/hrh/community/en/ [Accessed 12 Dec 2018]

36. Barron E, Clark R, Hewings R, et al. Progress of the healthier you: NHS diabetes prevention programme: referrals, uptake and participant characteristics. Diabet Med 2018;35:513-8.

37. Currell R, Urquhart C, Wainwright $P$, et al. Telemedicine versus face to face patient care: effects on professional practice and health care outcomes. Cochrane Database Syst Rev 2000;(2):CD002098.

38. National Institute for Health and Care Excellence (NICE) Behaviour change: general approaches Public health guideline [PH6], 2007. Available: https://www.nice.org.uk/Guidance/ph6 [Accessed 11 Jan 2018].

39. NICE. Behaviour change: individual approaches. Public health guideline [PH49], 2014. Available: https://www.nice.org.uk/ Guidance/6ph49 [Accessed 11 Dec 2018].

40. Zhang X, Yang S, Sun K, et al. How to achieve better effect of peer support among adults with type 2 diabetes: a meta-analysis of randomized clinical trials. Patient Educ Couns 2016;99:186-97.

41. Hill J, Peer N, Oldenburg B, et al. Roles, responsibilities and characteristics of lay community health workers involved in diabetes prevention programmes: a systematic review. PLoS One 2017;12:e0189069.

42. Davies MJ, Gray LJ, Troughton J, et al. A community based primary prevention programme for type 2 diabetes integrating identification and lifestyle intervention for prevention: the let's prevent diabetes cluster randomised controlled trial. Prev Med 2016;84:48-56.

43. Norris SL, Chowdhury FM, Van Le K, et al. Effectiveness of community health workers in the care of persons with diabetes. Diabet Med 2006;23:544-56.

44. Katula JA, Vitolins MZ, Morgan TM, et al. The healthy living partnerships to prevent diabetes Study: 2-year outcomes of a randomized controlled trial. Am J Prev Med 2013;44(4 Suppl 4):S324-32

45. Thankappan KR, Sathish T, Tapp RJ, et al. A peer-support lifestyle intervention for preventing type 2 diabetes in India: a clusterrandomized controlled trial of the Kerala diabetes prevention program. PLoS Med 2018;15:e1002575. 
46. Egbujie BA, Delobelle PA, Levitt N, et al. Role of community health workers in type 2 diabetes mellitus self-management: a scoping review. PLoS One 2018;13:e0198424.

47. Gatlin TK, Serafica R, Johnson M. Systematic review of peer education intervention programmes among individuals with type 2 diabetes. J Clin Nurs 2017;26:4212-22.

48. Jenkinson $\mathrm{CE}$, Dickens $\mathrm{AP}$, Jones $\mathrm{K}$, et al. Is volunteering a public health intervention? A systematic review and meta-analysis of the health and survival of volunteers. BMC Public Health 2013;13.
49. Choi NG, Kim J. The effect of time volunteering and charitable donations in later life on psychological wellbeing. Ageing Soc 2011;31:590-610.

50. Konrath S, Fuhrel-Forbis A, Lou A, et al. Motives for volunteering are associated with mortality risk in older adults. Health Psychol 2012;31:87-96. 